\title{
ÉRAMOS NIÑOS Y QUERÍAMOS CORRER Y JUGAR. LA EDUCACIÓN FÍSICA MÁS ALLÁ DE LAS NORMAS Y LOS MUROS DE LA ESCUELA
}

\author{
WE WERE KIDS, WANTING TO RUN AND PLAY. PHYSICAL EDUCATION BEYOND NORMS AND \\ SCHOOL WALLS
}

\section{ÉRAMOS CRIANÇAS E QUERÍAMOS CORRER E JOGAR. A EDUCAÇÃO FÍSICA ALÉM DAS NORMAS E OS MUROS DA ESCOLA}

\author{
Jhon Carlos Cortés Murillo ${ }^{1}$ \\ Johao Certuche Villada ${ }^{2}$
}

\section{Resumen}

\begin{abstract}
El presente estudio es un ejercicio interpretativo sobre el desarrollo individual y profesional de una persona del común permeada por la educación física, sus disposiciones prácticas y discursivas. En la primera parte, se hace una breve remembranza de la Educación física en Colombia; enseguida, se presenta la metodología empleada en este trabajo, a saber, historia de vida apoyado en el uso de entrevistas a profundidad que fueron derivadas del modelo multi-dimensional propuesto por Atkinson (1998). En tercer lugar, se presenta la narración de la protagonista; este relato ha aportado un nuevo paisaje de observación complejo y fértil que articula las experiencias del sujeto con los elementos sociales y humanos de la formación en la profesión. Finalmente, el artículo concluye afirmando que problematizar la educación física y su devenir en el tiempo a partir de las voces, relatos y narrativas de quienes la viven cotidianamente permite explicar hasta cierto punto el conjunto de sentidos y significados que subyacen en la relación que cada individuo entabla con el modelo preponderante de la disciplina.
\end{abstract}

Palabras clave: historia; relato de vida; educación física

\section{Abstract}

The present study is an interpretation of the individual and professional development of a regular person permeated by physical education, as well as its practical and discursive dispositions. The first part is a brief review of physical education in Colombia, followed by an explanation of the methodology used, namely, a life story supported by the use of in-depth interviews derived from the multidimensional model proposed by Atkinson (1998). In the third part, the protagonist narrates her story, which provides a complex and fertile new observation landscape that articulates the experiences of the subject with the social and human elements of education in the profession. Finally, the article concludes by stating that the problematization of physical education and its evolution over time, based on the voices, stories and narratives of those who experience it on a daily basis, makes it possible to explain, to some extent, the set of meanings and senses underlying the relationship of each individual with the preponderant model of discipline.

Keywords: history; life story; physical education

1 Estudiante de Maestría en Estudios Sociales de la Universidad Pedagógica Nacional. Antropólogo por la Universidad Nacional. Licenciado en Educación Física por la Universidad Pedagógica Nacional. Docente del Departamento de Investigación de la Corporación Universitaria Cenda; línea de investigación Motricidad y Desarrollo Humano. Correo electrónico: Jhon.cortes@cenda.edu.co.

2 Magíster en Educación con énfasis en Evaluación Educativa. Licenciado en Educación Física por la Universidad Pedagógica Nacional; docente del Departamento de Investigación de la Corporación Universitaria Cenda; línea de investigación Motricidad y Desarrollo Humano. Docente de planta de la Fundación Educativa de Inglaterra e English School, Bogotá. Correo electrónico: Johao.certuche@cenda.edu.co; johaocertu@gmail.com. 
O presente estudo é um exercício interpretativo sobre o desenvolvimento individual e profissional de uma pessoa comum permeada pela educação física, suas disposições prática e discursivas. Na primeira parte, é realizada um breve percurso histórico da educação na Colômbia; em seguida, apresenta-se a metodologia utilizada neste trabalho: história de vida, através de entrevistas a profundidade derivadas do modelo multidimensional proposto por Atkinson (1998). Na terceira parte, é apresentada a narração da protagonista; este relato contribui com um ponto de vista complexo e fértil que articula as experiências do sujeito com os elementos sociais e humanos da formação na profissão. Finalmente, o artigo conclui afirmando que problematizar a educação física e a sua evolução no tempo a partir das vozes, relatos e narrativa daqueles que a experimentam dia-a-dia permite explicar em certa medida o conjunto de sentidos e significados subjacentes na relação que cada indivíduo estabelece com o modelo preponderante da disciplina.

Palavras chave: história; relato de vida; educação física

Fecha de recepción: 12 de julio de 2016

Fecha de aprobación: 18 de noviembre de 2016

Para citar este artículo:

Certuche, J. y Cortés, J. (2017). Éramos niños y queríamos correr y jugar. La educación física más allá de las normas y los muros de la escuela. Lúdica Pedagógica, (25), 33-46. 
La historia de cada uno no por ser singular, deja de ser universal. Cada vida humana expresa de manera subjetiva toda la objetividad social. Cada historia de vida es una narración individual portadora de significaciones colectivas donde se vierten enunciados públicos partiendo de enunciados privados.

FERRAROTTI

\section{REMEMBRANZA DE LA EDUCACIÓN FÍSICA EN COLOMBIA}

Hablar de la educación física en Colombia ha de tener como punto de referencia el reconocimiento de sus constantes cambios y transformaciones a lo largo de su historia. Una historia que, al parecer, carece de argumentos para dar sentido y significado completo a lo que la disciplina es y representa en la actualidad educativa del país. Sus muchas formas de ser, y con ellas sus múltiples propósitos, redundarán como bucles que no solo le asignan identidad a la actualidad educativa, sino que también la convierten en garante de su permanencia como práctica y hecho social. Asimismo, a la educación física se le atribuyen ciertos valores y potencialidades en el escenario educativo, que aunque en muchas ocasiones correspondes a la realidad, aún no es claro cómo dicha práctica ha llegado a tal momento de evolución y estructuración epistemológica. Al respecto, el Ministerio de Educación Nacional (2010) plantea que

La educación física, recreación y deporte puede ser considerada una disciplina privilegiada para la formación integral de los individuos, en la medida que tiene gran acogida en la población estudiantil como área fundamental del currículo y su importancia viene creciendo para la comunidad educativa en general. (p. 9).

Así, la educación física en la escuela, secundada por la formación docente en el área, parece estar permeada por la ilusión de su potencial social y pedagógico, que desconoce muchos de los elementos de su trayectoria e historia. En consecuencia, quedan a la deriva las posibilidades de comprenderla mejor, y de ese modo permitirle continuar sus procesos de transformación, según sean sus demandas y contextos.

La historia reconocida de la educación física en nuestro país se centra en la documentación teórica acerca de sus fines, transformaciones, usos, modelos, tendencias y discursos epistemológicos. Los intentos por consolidar el constructo de la historia de la disciplina en el orden nacional -quizá por la percepción misma que se tiene de la historia en el sentido lineal y formal del términoparecen estar confinados a las obras Historiografía de la educación física (Chinchilla, 1998a); La educación física en el proceso de la modernización (Chinchilla, 1998b); Historia de la educación física a través de sus normas (Vaca, 1987); Historia del alma mater de la educación física en Colombia (Vaca, 1993); La educación física y el deporte en Colombia. Una historia (Contecha, 2000) e Historia de la Educación Física en Colombia como profesión, 1936-1986 (Gómez, y Parra, 1986). Estos esfuerzos aún resultan insuficientes, sobre todo porque se centran en el campo de la formalización disciplinar, en los cambios normativos y en las declaraciones estatales, y en muy pocas ocasiones - para no cerrar la puerta a la posibilidad de que existan otros trabajos históricos-, se ha dado luz y oportunidad a escuchar, ver, comprender y ser desde la voz de los sujetos que la viven a diario (más allá de su fama, producción académica, rol institucional o jerarquía social), pues dicha voz permanece casi oculta. Aquellos otros relatos llenos de experiencias, ideas, emociones sobre la disciplina parecen extraviarse en los corrillos, en los patios, en las aulas, perdiendo, y en algunos casos desconociendo, su valor para comprender la historia de los sujetos y con esto de la disciplina en sí misma, al menos desde una perspectiva alternativa a la convencional. Por esta razón es fundamental comprender que la historia tiene vida en el trasegar por los recuerdos, en el encuentro de las memorias que se oponen al olvido de lo que fuimos y somos, lo cual denota la trascendencia del ser humano. Así, mediante la evocación y reconstrucción de los recuerdos es posible comprender al individuo en la trama de las significaciones y los cambios en el tiempo; se captura el pasado y se trae al presente, allí se evoca la vida.

De esta manera, con la intención de contribuir a consolidar un constructo que le dé significado a la historia de la educación física nacional, se apuesta por buscar formas distintas de comprender o ilustrar dicha historia. De acuerdo con Ferrarotti: "nuestro sistema social está todo entero en cada uno de nuestros actos, en cada uno de nuestros sueños, delirios, obras, comportamientos y la historia de este sistema está toda entera en la historia de nuestra vida individual" (2007, p. 27). En este sentido, se reconocen como valiosos y significativos 
aquellas historias de vida individuales que reseñan una relación directa con la disciplina, más aún cuando dicha relación determina la elección de un estilo de vida, ya sea por pasión, o por la incidencia del contexto ante los avatares de la vida moderna: "Relatar la vida no es vaciar una sucesión de acontecimientos vividos, sino hacer un esfuerzo para dar sentido al pasado, al presente y a lo que este contiene como proyecto (Carvajal, 2005, p. 189). Además, reconocer el sentido que un sujeto le atribuye a un escenario como el de la educación física en su propio relato de vida es sin duda una posibilidad y oportunidad única para entender dicho escenario. Esto claramente no es un intento más por masificar significados, ni mucho menos por plantear las percepciones individuales en términos universales. Se trata de reconocer su valor como significante en un contexto particular, que carga consigo el conjunto de valores, deseos, intenciones, acciones y lógicas de un periodo histórico, y a partir del cual se espera reconocer de forma alternativa la historia de la disciplina inscrita en ella.

Teniendo en cuenta lo anterior, Hernández (2003, citado por Arcila, Mendoza, Jaramillo y Cañón, 2010) señala que "no se debe considerar la mente como un instrumento donde se depositan los significados sino, más bien como creadora de ellos y esta creación no puede desligarse del mundo circundante en el que se encuentra inmerso el sujeto" (p. 38). Esto quiere decir que los significados construidos por un sujeto inscrito en el contexto de la educación física sin duda son el reflejo del impacto que dicho contexto tiene sobre sí mismo, que permea la comprensiones superfluas de la rutina o de la eventualidad temporal, para ser asumidas como propias, como configuraciones subjetivas que dan sentido al ser y estar en el mundo del sujeto.

\section{METODOLOGÍA}

El presente estudio es un ejercicio interpretativo sobre el desarrollo personal y profesional de una persona del común; un sujeto que sin grandes pretensiones de popularidad, fama o semejantes ha sido permeado por la educación física y sus disposiciones prácticas y discursivas. El trabajo permite hacer un acercamiento a los aspectos más significativos del protagonista de este relato, y a su vez examina el tejido que configura la disciplina en sus nudos más simples y desconocidos.
La decisión sobre su participación en este estudio se tomó considerando la relación que existe entre los eventos que marcan la vida personal y las decisiones sobre un estilo de vida profesional, y que se encuentra atravesada por sus experiencias educativas en el campo de la educación física. En consecuencia, este ejercicio se presenta como una apuesta por comprender la urdimbre que se teje entre un campo de saber (educación física), las coyunturas de la vida y los cambios históricos de la disciplina. En este sentido, el trabajo se aparta de la reconstrucción histórica convencional basada en planteamientos teóricos, o en algunos casos en la reconstrucción biográfica de sus más prodigiosos representantes. En cambio, el propósito de este trabajo gira en torno a la identificación de significados atribuidos a la disciplina desde una narrativa biográfica que se abstrae de los convencionalismos de la investigación histórica de archivo. Por este motivo, se hizo un rastreo de los momentos y recuerdos más relevantes en la vida de la protagonista de esta historia, destacando los elementos que caracterizan cada uno de ellos. Del mismo modo, se identificaron las posibles influencias de sus experiencias de vida (contexto familiar y social), su vida escolar inicial (con énfasis en la educación física) y su formación profesional (licenciada en Educación Física).

Considerando las pretensiones del estudio, se optó por el método historia de vida, apoyado en el uso de entrevistas a profundidad derivadas del modelo multidimensional propuesto por Atkinson (1998). Dicho modelo se modificó para atender a las intenciones de esta investigación, pues en él se reconoce la entrevista a profundidad como una estrategia de indagación que busca obtener información desde la voz de los actores con el propósito de comprender su pasado, sus experiencias y razones dentro de un marco de referencia mayor. Para esta entrega del ejercicio se definieron cinco dimensiones: escolarización básica; educación física y deporte como práctica sociocultural, factores sociales, educación física y vida personal, y visión de futuro. En ellas la educación física se asume transversal a las demás y adquiere distintos matices de acuerdo con las relaciones que se establecen con ella.

La ruta metodológica diseñada para este proceso se resume de la siguiente manera: (1) modificación del modelo Atkinson (1998), (2) generación de preguntas (cuestionario), (3) prueba piloto y generación de nuevas preguntas incorporando la lectura analítica como un 
modelo de trabajo útil a la interpretación y al diseño de preguntas de indagación, (4) aplicación de instrumento, y (5) lectura analítica de las entrevistas y generación de nuevas preguntas.

Con respecto al último paso, se exponen a continuación los elementos más generales de la lectura analítica, entendida como "leer para comprender", a partir del entendimiento, la retención, la reflexión y la proposición (Manayay, 2010):

1. Comprensión (por qué de las cosas, cómo surgen, cuál es el propósito según lo expuesto en el texto)

2. Inferencia (sentidoy significado de los enunciados)

3. Síntesis (resumen)

4. Evaluación (tipo de información y contexto)

5. Opinión y juicio

6. Redacción (generación de preguntas o interpretaciones)

\section{"EL BARRIO DE LOS MARCHISTAS": UNA HISTORIA DE LA EDUCACIÓN FÍSICA QUE TRASCIENDE LOS MUROS DE LA ESCUELA}

Vivo en un lugar al que llaman el barrio de los marchistas. Nací el 20 de mayo de 1989 en Bogotá. Soy la menor de cuatro hermanos y siempre he vivido en esta ciudad en el barrio Potosí en la localidad de Ciudad Bolívar, de hecho, soy la única entre mis hermanos que siempre ha vivido en la misma casa. Mi mamá es del Tolima y mi papá del Huila. Se conocieron en el Caquetá y llegaron a Bogotá porque mi papá aceptó una oferta de trabajo hace unos 35 años. ¿Sabes? Ciudad Bolívar ha sido estigmatizada como una zona asociada a la muerte, no sé si es por estar viviendo ahí, pero, a todo se acostumbra uno, la verdad he pensado vivir en otro lugar, aquí se ven muchas cosas.

Mi mamá y mi papá llegaron a vivir en un barrio llamado Patio Bonito y ahí compraron un lote para levantar su casa, luego nos vinimos para acá. También han vivido en el Perdomo y en el Olaya. De pequeña compartí muchas cosas con mis amigos de la cuadra, ya ninguno vive acá; Jason, Arnol, Adriana, Arsy, Iván, todos se han ido y no los he vuelto a ver. Con ellos jugábamos mucho, juegos tradicionales que ahora no se ven. Jugábamos tarrito, cogidas, rejito quemado, todo ese tipo de actividades, yermis... me parecen juegos muy sanos y chéveres que se han perdido, esta generación ya no vive cosas así. Para ese entonces Potosí era un barrio que empezaba a surgir, había pocas casas, lotes con maleza y espacios desocupados. Para jugar a las escondidas y otras cosas había mucho espacio donde ocultarse, casas en obra negra, potreros, arrumes de madera y otras cosas, ahora para jugar hay que correr tres cuadras para esconderse. Hoy Potosí está muy poblado.

Recuerdo que toda la vida estudié en un colegio aledaño a Potosí, fue toda mi primaria y bachillerato, se llama Arborizadora Alta. Cuando yo estudié allí, ese colegio era uno de los más importantes de la localidad, tenía la educación más avanzada. El colegio está ubicado sobre la montaña, jahora que lo veo! ha desmejorado mucho. Cuando estudié era bueno. Durante un tiempo dos de mis sobrinas estudiaron ahí, de hecho, una de ellas todavía lo hace. Hace muy poco tiempo fui a una reunión y el colegio ha cambiado muchísimo, se ha vuelto terrible, las paredes rayadas, parece una cárcel y no un colegio. En mi tiempo era un colegio normal, agradable, su cancha, su parquecito, los profesores bien, los estudiantes... ¡Bueno! de todas maneras las épocas cambian mucho los pensamientos de las generaciones.

Déjeme decirle que cuando era pequeña no me gustaba ir a la escuela porque había una niña que tenía síndrome de Down, ella me daba mucho miedo, esa niña me perseguía y yo me metía debajo de las mesas; imagínate que mi mamá me decía que me daría regalos si yo me quedaba en la escuela. Ahora que lo sé, la niña solo quería ser mi amiga, pero como en ese entonces yo no lo sabía... le huía. Cuando ella veía que yo la evadía, se enojaba y me quería pegar. A los profesores les parecía algo normal, además, ella era una niña muy grande, ¡me daba mucho miedo! Fue traumático estar allá durante ese tiempo, es un recuerdo terrible de mi paso por la primaria. Yo no podía estar en paz conmigo misma, siempre estaba pensando que ir al colegio era enfrentarme al miedo que le tenía a esa niña. Para mí era horrible salir al descanso o a desayunar; recuerdo un kiosco que se hallaba junto a nuestros salones [primaria], ahí nos reuníamos todos los niños a tomar las onces y a compartir, pero cuando me encontraba con la niña yo entraba en pánico. Ese kiosco estaba para los niños más pequeños, nos reunían ahí para que los niños más grandes no nos pegaran y evitar que los estudiantes de bachillerato nos robaran las onces, pero... ¡imagínate mi caso!, usábamos un lugar especial para evitar que nos pegaran, pero a mí me perseguía esta niña. Ella sabía que yo le tenía miedo, entonces, me perseguía. Aunque lo que te cuento fue muy difícil para mí, también hubo cosas muy importantes, tengo muy gratos recuerdos del profesor que me daba todas las materias, Giovanny Luna se 
llama, o quizá se llamaba, no sé si todavía vive, en todo caso era muy buen profesor y quería mucho a los niños. Él era muy comprensivo y por eso le [sic] quería mucho, enseñaba con amor, se veía que le gustaba lo que hacía. En sus clases me gustaba mucho aprender, siempre aprendía cosas nuevas y tenía amigos con los que jugaba. Me gustaba aprender juegos; juegos de calle como a las escondidas, o los inventábamos, jugábamos con pelotas, tapas de gaseosa, con palos de escoba, con lo que hubiera.

Antes el colegio contaba con zonas verdes, tenía mucho espacio, han construido más salones y esas zonas verdes han desaparecido, han puesto muros y el colegio se ve desagradable, ya no hay forma ni siquiera de correr, ya no hay espacio. Ahora el colegio solo tiene dos canchas, las zonas verdes murieron. Cuando yo estudié allí, el colegio tenían su rejita, ipero es que ahora son muros! de hecho hay algunos salones que ni siquiera tienen una ventana, cuando yo estudié tenía ventanas y visión al exterior, ahora son sólo muros, desde la calle se pueden ver.

\section{Sobre los "profes" de educación física}

Tuve cuatro en mi vida escolar, todos eran profesionales del área pero totalmente diferentes entre ellos. Empecemos por el de primaria, su nombre era Enrique, compartí con él desde primero hasta quinto. Era muy amargado, me acuerdo que siempre nos sentaba en la cancha cuando no le hacíamos caso, nos dejaba ahí sentados como media hora sin hacer actividad, era algo traumático porque éramos niños y queríamos correr y jugar. Las clases eran cosas populares como cantar y aprender canciones. Él era un tipo de carácter fuerte, nos regañaba mucho. Era muy chistoso cuando uno lo veía sonreír pues poco lo hacía. Sus castigos eran dejarnos quietos, con él, por unos pagaban todos; si un niño era desordenado todos debían sentarse en el patio; le confieso que en primaria nunca se me pasó el deporte por la mente, me parecía algo aburrido y con mi familia nunca tuve la oportunidad de compartir cosas así. Mi mamá siempre estuvo dedicada al hogar y mi papá al trabajo, casi no salíamos y no había la oportunidad para el deporte. Con ellos nunca practiqué ningún deporte ni hice ningún tipo de actividad física. Con mis hermanas sí salíamos a jugar en la cuadra, quizá por eso me gustan tanto esos juegos de los que ya te hablé. No teníamos hábito alguno, de vez en cuando, no era algo rutinario, no era del plan de fin de semana, salimos al Parque El Tunal. Recuerdo que una vez llevamos un balón y jugamos pelota. En ese parque existían atracciones mecánicas, cuando era muy pequeña en alguna oportunidad montamos, hoy ya no existen.
En primaria lo único que me inquietó del deporte fue mi hermana, ella era atleta del colegio y le iba muy bien, salía a representar al colegio en competencias y cosas así, Yo la veía como un ejemplo, quería ser como ella. Cuando pasé a sexto vino el segundo profe, aunque solo estuve un año con él. Fue mi director de curso, se dedicaba a hacer lo suyo y ya, no se le veía agrado. Sus clases eran trabajos de deporte, vamos a trabajar tenis decía; entonces... volea, revés y esas cosas, en todo caso era bueno con eso. Trabajaba por ciclos; baloncesto, atletismo; siempre abordaba diferentes deportes. Ah... ahora que recuerdo le gustaba mucho trabajar porras, armaba grupitos e íbamos a otros colegios y también hacia un concurso en el colegio, a veces no se trataba de gusto personal, sino de una obligación escolar. Él era un profe más querido que Enrique, "me parecía que era muy cariñoso con las niñas" y con los hombres era muy fuerte, ¡no sé! yo siempre le guardé cierta distancia. De aquel entonces recuerdo los concursos de porras y el día olímpico, salíamos a marchar por las calles del barrio con pancartas y disfrazados de deportistas. Se hacía un match, se practicaban diferentes deportes y salíamos a hacer una caminata por el barrio. Se hacían campeonatos de baloncesto, fútbol, la carrera de atletismo, voleibol y otros deportes y juegos para niños.

Ahora bien, le contaré la parte importante, viene el profe que marcó mi vida para decidirme en el deporte. Con él trabajé octavo, noveno y décimo. Por cosas de la vida él se fue del colegio y yo cambié de jornada escolar. Germán Olaya entró al colegio motivando a los estudiantes con el cuento del baloncesto, formó su escuela y hacía los entrenamientos después de clases. Los equipos que armó salían a representar al colegio, entonces, cuando yo vi eso, recordé lo que veía en mi hermana en la primaria, ¡salir a representar al colegio!, yo también quería hacerlo y esa era una buena oportunidad. Cuando quise ingresar, él me hizo unas pruebas, había mucha gente que quería pertenecer al equipo, entrenaban muchos, pero el equipo solo se formaba por doce personas. Afortunadamente puede ingresar y empezamos a participar en diferentes zonas, juegos intercolegiados y cosas así, siempre nos iba muy bien. Él es un excelente entrenador, creo que ahora trabaja con la liga de Bogotá

Recuerdo que con él salíamos a jugar baloncesto en diferentes colegios, en especial, recuerdo un partido contra el colegio Nuestra Señora del Pilar. El partido lo ganaron ellas, eso fue algo que nos sorprendió mucho porque nosotros estábamos en nuestra casa, eran unos juegos intercolegiados, disputábamos la final para ir al nacional en Cartagena; entonces, el entrenador hizo todo lo posible para 
que jugáramos de locales en Arborizadora Alta. ¡Fue, mejor dicho...! El Coliseo lleno de padres y de estudiantes, todos motivados y animados con la fiesta lista, al final... perdimos, jese equipo era muy bueno! Fue algo tenaz.

Antes de lo que esperaba salí del equipo, yo entré pero realmente no era muy buena jugadora, hacia parte de la banca, aunque salí a competir fueron pocas las veces que jugué, ¡no era muy buena! Me sentía frustrada, siempre estaba sentada. Pero bueno, eso también es parte de esta historia, déjeme y le sigo contando. Todos los años este profe organizaba la carrera atlética del colegio y yo siempre la ganaba. Cuando él notó eso me dijo que yo tenía buenas habilidades para el atletismo y me sugirió seguir por ahí, además, él me decía que pronto se iría del colegio y con seguridad el equipo de baloncesto se acababa, él me dijo que el atletismo me abría espacios.

En aquel entonces él vivía en el Tunal. Yo estudiaba en la tarde y me pedía que nos encontráramos en las mañanas para ir a correr a la pista del parque metropolitano que lleva el mismo nombre, "Tunal". Yo le hacía caso, pero siempre iba con una compañera... corríamos y ya. A mí me llamaba mucho la atención correr, sabía que en ese entonces tenían [sic] potencial, además, mi hermana también corría y yo tenía eso muy presente, iyo me las creía! Este profesor me animaba mucho, siempre me repetía que tenía muy buenas cualidades, tanto así que jestuvo dispuesto a salir a entrenar conmigo en las mañanas! Siempre me apoyaba y me decía que era buena.

Para ese mismo tiempo tuve la oportunidad de estudiar con un compañero que pertenecía al Club Potosí, un club de atletismo que quedaba ahí en el barrio. Ya los juegos de la cuadra se han ido y empiezan a aparecer mis amigos de entrenamiento; José Oñate, James Rendón, Pilar Rayo. La mayor parte del tiempo me la pasaba entrenando, iya no jugaba!, ahora entrenaba. Yo no tenía la menor idea [de] que ese club existía, viviendo tantos años ahí y no lo supe, pero déjeme decirle que aún existe, ya no entrenan en el Tunal, no sé si conoces [sic] el mito del Palo del Ahorcado, te cuento que ahora trabajan allá, marcaron una pista para entrenar, su entrenador, Giovanni Castro la hizo, él también estudió en Cenda. José Oñate me invitó a entrenar con ellos, me dijo que era muy cerca de mi casa. El gimnasio al que ellos iban, ¡tan solo quedaba a dos casas de la mía! José me dijo que sería bueno pertenecer a ese grupo, que él veía cosas buenas para mí, pero ¡no! la verdad, a mí me daba pereza. Sabía que me tocaría madrugar y siempre me ha parecido muy jarto hacerlo, entonces ¡no! yo le tenía pereza a eso.
Yo la verdad no le seguí la corriente, pero mi amiga, de la que ya te hablé, me decía que sí, que fuera, porque ella también quería pertenecer al equipo. Su hermano era campeón nacional, entonces ella al igual que yo quería ser como su hermano. Ella me decía que le gustaría ir, pero no quería hacerlo sola y por eso yo la acompañé. El día en que fuimos estaba haciendo mucho frío, al principio yo me quedé sentada, pero el frío me impulsó a correr. De a poco empecé a meterme en el cuento y continué acompañando a mi amiga, así empecé a entrenar. Me acuerdo que cuando iba me sentaba en las gradas a verlos correr, a ver cómo entrenaban. Giovanny se acercaba y me decía; "vaya corra, qué pereza verla ahí sentada, ¿a qué vino acá? ¿A aguantar frío?" Bueno, voy a correr... y cuando empezaba a trotar me gustaba. Según Giovanny yo tenía talento. "Venga... usted porque no entrena, mire que le va muy bien" me dijo ese día. Bueno, Giovanni Castro era un docente de un colegio cercano a mi casa; él, al igual que Germán, quiso formar un grupo de deportistas, pero lo hizo en el atletismo. Destinaba su tiempo libre al entrenamiento de sus muchachos, renunció al colegio y se dedicó solamente al entrenamiento. Giovanni me motivó mucho, me convenció de eso, me dijo que entrenara juiciosa, que veía potencial en mí.

Cuando pude lograr el hábito todas las mañanas, él me dijo que tenía que escoger entre atletismo o baloncesto. "Los entrenamientos de baloncesto son en la noche y los de atletismo en la mañana, además, tú estudias en la tarde y eso te cansa mucho". Él me decía que sabía que una cosa podía complementar la otra, pero que yo no podía cantar y silbar al tiempo, debía escoger. Después de todo le dije: "me quedo en baloncesto", entonces le comenté a Germán Olaya y de inmediato me reprochó "quédese en atletismo, yo me voy del colegio y esto se acaba. Yo no creo que algún profesor o la persona que me remplace saque sus noches para venir a entrenar". Esos entrenamientos no eran pagos para el profe Germán, era algo que le nacía, le gustaba tener su equipo; entonces le hice caso, empecé a entrenar con Giovanni todas las mañanas. Llevaba dos meses entrenando atletismo (carrera). Él entrenaba atletas de varias modalidades, pero quería formar un grupo de marcha atlética y trataba de convencernos para pasar a marcha. Al igual que a todos, él me dijo que me metiera, pero ¡no! eso me parecía muy chistoso, yo le dije que no, por ahora correr, le respondí; entonces me dij:; "mire, hagamos una cosa, va a haber una competencia ahora cerca, usted ya tiene las bases de correr, pues si quiere aprenda a marchar y compite en esa carrera, si le va bien, entonces usted decide si sigue marchando o se queda corriendo". Esa idea 
me inquietó mucho, recordé a mi hermana y mis deseos de salir a competir, entrené un mes completo, fuimos a competir, [la competencia fue acá en Bogotá] una copa nacional, obtuve el segundo lugar y clasifiqué para ir a Medellín, ifueron unos resultados muy buenos! ¡Llevaba solo dos meses entrenando! Uno de atletismo carrera y uno en marcha, entonces dije bueno, me quedo en marcha, fui a Medellín y allá también el segundo puesto.

Medellín es quizá el punto competitivo más importante en mi vida, marcó todo para mí. Llevaba muy poco en el deporte. Tuve que enfrentarme con gente de mucha trayectoria y con mucha experiencia. $\mathrm{Al}$ quedar en segundo lugar, eso me abrió muchas puertas, me fortaleció, me hizo creer más en mí y convencerme [de] que debía estar ahí. Después de todo Germán fue el responsable de mi gusto por el deporte. Gracias a Germán pude tener un proyecto de vida muy bueno. Ahora me gusta muchísimo lo que hago, soy quien soy gracias a los motivos que Germán me dio, le agradezco llevarme al camino del deporte, él descubrió ese talento en mí y le estoy profundamente agradecida; a Germán nadie lo quería en el colegio, los profesores siempre estaban en su contra. Él tenía su equipo de baloncesto y salía junto con los estudiantes a muchas competencias, entonces los demás profes lo veían como el fastidio que no dejó hacer clase. Lo que concierne a la educación física que él debía ofrecer fue poca. Él siempre estaba muy metido en el cuento del baloncesto, muchas veces el baloncesto le evitó hacer las clases de educación física, en realidad, la educación física fue remplazada por el entrenamiento de baloncesto. Prácticamente la educación física del colegio la hice jugando baloncesto. Casi todo el equipo estaba en mi curso, y el profesor [Germán] también era el entrenador. Él era tan apasionado por el baloncesto que cuando debía hacer clase de educación física con el curso al cual yo pertenecía, enfatizaba en el entrenamiento y apartaba a los integrantes del equipo para hacer otros ejercicios. Él también promovía la escuela, armaba los campeonatos y nos llevaba a competir a otros lugares. La clase de educación física me parecía muy chévere, fue la oportunidad de empezar a entrenar y a compartir otros espacios, con otros colegios, con otras personas. Jugando baloncesto fue que me incliné por el atletismo. Cuando Germán hacía pruebas de selección o de entrenamiento me iba muy bien corriendo. Fue Germán quien me indicó el camino del atletismo y por supuesto me pidió probar creyendo que me iría bien; para eso, fueron muy importantes las carreras que él mismo organizaba en el colegio, ahí fue cuando me convencí de lo que Germán me decía. Descubrí que era buena para correr. En el colegio hacían como una maratón, cerraban las vías aledañas y marcaban un circuito donde corríamos por cursos. Fueron varias pruebas las que pude ganar.

Luego que Germán partió llego una profesora, ella todavía está en el colegio, de hecho, la educación física del colegio ha desmejorado, yo creo que ella es en buena medida responsable de eso, es una profesora muy pasiva. En el tiempo que trabajé con ella, no vi que motivará a la educación física. Los profesores que le antecedieron hacían el concurso de porras, carreras atléticas, el equipo de baloncesto, el equipo de fútbol del colegio; en cambio ella, no he escuchado que haga nada, se dedicó sólo a la clase de educación física y ya. Las clases de educación física con ella eran: tome el balón y vaya juegue; no sé, la verdad... esa es la idea que tengo sobre lo que hice con ella, no sé si era porque yo andaba muy cansada por los entrenamientos, entonces, no quería hacer nada y ella me llamaba la atención, ella quería ser regañona pero no lo era. No sé si es porque creo que no hizo nada, o realmente esa profesora no hacía nada.

Recuerdo que en grado once cuando debía hacer educación física, yo me sentaba en las gradas, recuerdo que otros muchachos jugaban con un balón en la cancha, no me acuerdo de la clase. ¿Sabes? Al final creo que la educación física en mi bachillerato fue buena, a excepción de pocas experiencias tengo buenas bases, experimenté cosas muy bonitas, porque viví diferentes deportes, porque me enamoré de la educación física. En cambio la educación física en primaria no me dejó nada o casi nada, faltó bastante; es la etapa más importante para desarrollar las habilidades, pero el profesor se dedicó a ser el coco del colegio y no el de educación física. No era cosa de miedo, pero cualquier error que un niño cometiera, y ieste personaje nos dejaba sentados! En realidad hicimos poca actividad con él. Sin embargo, puedo estar tranquila y decirte que la educación física es todo para mí gracias a lo que viví en el bachillerato y el atletismo, ahora trabajo en educación física y mis proyectos se han hecho realidad. Soy una persona profesional, tengo una visión de vida diferente, he conseguido mis cosas $\mathrm{y}$ he proyectado todo gracias a esta profesión, me siento orgullosa y me siento contenta al saber que he podido ayudar a niños y otras personas por mi profesión. Tengo la bendición de compartir con mi hija muchas de las cosas que he aprendido en educación física. He tratado de inculcarle el deporte y la salud, trato de ser un ejemplo para ella. 


\section{La vida profesional}

Pero sigamos con el deporte, yo empecé en el atletismo cuando estaba finalizando grado décimo. Tenía resultados buenos, pero, estaba preguntarme... [sic] ¿Qué voy a hacer al salir de once? Las oportunidades en la localidad donde vivo son pocas, allá vivimos personas humildes, personas con muy pocos recursos económicos, y por lo mismo no es factible la universidad. Allá todo el mundo cuando termina grado once solo tiene dos opciones; es el Sena, o vaya a conseguir un empleo en una empresa. Las oportunidades para la educación superior son muy difíciles. Cuando entré a grado once tenía que hacerme a la idea [de] que, al finalizar el bachillerato, terminaba también mi carrera deportiva, además, tenía mucha presión, hace muy poco mi papá había fallecido, yo apenas tenía 15 años. Mi carrera deportiva fue ese escape al dolor. El atletismo llegó a darme fuerza por la ausencia de mi papá. Como él trabajaba en la casa yo siempre lo encontraba al regresar del colegio. Enfrentar ese vacío no fue fácil, "lo más difícil de la muerte es darse cuenta [de] que la gente desaparece, en verdad dejan de existir, sus cuerpos ya no están"; entonces llegó el atletismo y llenó el vacío junto con Giovanni Castro. Él fue una persona muy importante en mi vida, yo lo quiero mucho. Él me colaboró bastante, me quedé en el atletismo porque él me animó a practicarlo y por eso me ofrecieron mi estudio, obviamente también por mis resultados. Cuando conocí a Giovanni, poco tiempo atrás él había perdido una deportista muy buena, ella se fue con otro entrenador. Para él fue muy duro porque junto a ella habían ganado una medalla en un suramericano y otra en un nacional; fue un golpe tenaz. Él, al igual que yo estaba pasando por una pérdida y tuvimos una muy buena relación como amigos, como papá. Él siempre me estuvo apoyando en todos esos momentos. Cuando empecé a estudiar me apoyó en todo, para fotocopias, trabajos, pasajes, eran muchas cosas, él me colaboró mucho.

Cuando salí de once empecé a entrenar mañana y tarde pues había cambiado de categoría, los entrenamientos eran más exigentes. Cuando estuve en décimo y once [sic] hacía una prueba de $10 \mathrm{~km}$, al salir del colegio y cambiar de categoría pasaba a realizar pruebas de $20 \mathrm{~km}$. Tenía que entrenar mañana y tarde. Eso me ocupaba todo el día. Entré al grupo de apoyados del IDRD pero de todas maneras el apoyo era mínimo. Eran como $200 \mathrm{mil}$ pesos, tenía alimentación, apoyo para transporte, y con esa plata aportaba en mi casa. Esos $200 \mathrm{mil}$ realmente no son nada; pero yo estaba sola, no tenía responsabilidades de hijos, de nada... ipues los 200 mil eran una maravilla! Al final de todo en la casa hacía falta muchas cosas, sin mi papá las cosas eran más duras y mi hermana era quien aportaba todo, además, mi mami siempre ha sido aquejada por la enfermedad. Para mi hermana fue ¡tan duro!, muchas veces me dijo: "venga... ayúdeme que yo ya no puedo sola”. ¡Pobre mi hermana... su angustia era inocultable! Me costaba mucho no poder ayudar, casi me retiro. Terminé grado once y seguí entrenando. Mi hermana me decía que no siguiera, que me retirara porque yo debía aportar a la casa. Ella me conseguía trabajos en todo lugar y yo siempre le sacaba el cuerpo, de todas maneras a mí me gustaba mucho el atletismo y mi mamá siempre me apoyó muchísimo, no podía hacerlo con dinero pero sí moralmente, le gustaba lo que hacía y quería que siguiera en esto. A mi mamá le encanta que haga deporte, ella me apoya muchísimo, siempre ha estado muy pendiente de mí, me dice que no me salga de entrenar porque he logrado muchas cosas con el atletismo; mi carrera, he viajado, he conocido muchos lugares. El apoyo moral de mi mamá ha sido constante y sin desfallecer, siempre me decía que no me retirara, que era una buena oportunidad, siempre estaba ahí, para mí era más importante el apoyo emocional que el económico. "Ahorita pueda que no tengamos plata y estemos mal, pero más adelante se verá el esfuerzo" me decía. Mi mamá me contaba que le gustaba mucho el atletismo porque ella era muy buena cuando lo practicó, me contaba que le gustaba llegar a la meta, levantar los brazos, y tener esa sensación de ganadora, de seguro allí nace todo su respaldo a lo que yo hago.

En la primaria nunca salí con mis papás a ningún parque y en el atletismo tenía la oportunidad de viajar por todo el país, igratis!, me quedaba en los mejores hoteles, la mejor comida, para mí eso era muy importante porque nadie tenía la posibilidad de hacer lo que yo podía hacer. Cuando yo decidí abandonar el atletismo por la necesidad de trabajar luego de graduarme del colegio, hubo una competencia en Bogotá; fueron los primeros $20 \mathrm{~km}$ que hice. En ese entonces competimos como 15 deportistas. De los 15 solo dos terminamos la prueba: una muchacha de Boyacá y yo. Recuerdo tanto que la gente de la tribuna decía, no, que se retire. Yo llevaba $20 \mathrm{~km}$, fueron 50 vueltas, entonces la gente decía, ya todo el mundo se retiró y ella... ¿por qué sigue dando vueltas ahí? Hasta mi entrenador me decía, Andrea retírate ya... ¡No! yo termino. Gracias a Dios pude terminar la prueba. Por fortuna ese día asistieron algunos dirigentes del IDRD y me ofrecieron la beca, el IDRD me becó toda mi carrera. Me sentí muy feliz. Bueno, me becaron realmente los resultados deportivos. Los deportistas están clasificados en rangos. Cada uno obtiene apoyos 
según el nivel que posea. En ese momento existía un programa llamado centros de perfeccionamiento deportivo, creo que ya no existe. Reclutaban a todos los deportistas de diferentes modalidades para llevarlos al alto rendimiento apoyándolos con alimentación, transporte, y también universidad.

Cuando ingresé al programa la trabajadora social me ayudó mucho. "Venga para acá, ¿qué le gustaría estudiar?", me dijo. Habían [sic] diferentes opciones, la Universidad Piloto, la Universidad Cooperativa, bueno, habían [sic] diferentes instituciones. A mí siempre me ha llamado la atención el deporte, pero siendo sincera, la docencia no. Para enseñar no quiero. A mí me llamaba más la atención el diseño gráfico, diseñar, moldear, eso siempre me llamó la atención más que la educación física. Pero Giovanni me aconsejaba, "guíese por algo que le dé futuro, que usted sepa que va a estar bien". Cenda era la única Universidad que tenía convenio directo con el IDRD; con las otras universidades, el IDRD desembolsaba el dinero y uno tenía que ir a cambiarlo, pero con Cenda el trato es directo entre IDRD y Cenda. No sé qué tratos tenían ahí, creo que el IDRD prestaba algunos escenarios y por esa razón tenían los convenios o las becas. Entonces Giovanni me decía: "son cinco años de estudio, métase en algo seguro donde sepa que no va a dejar de estudiar, sepa que el convenio del IDRD va [a] durar mucho porque Cenda no tiene escenarios". Al principio yo quería estudiar entrenamiento deportivo pero Giovanny otra vez me dijo; "haga de una vez la profesional.... Finalmente yo le hacía mucho caso, él era como mi papá.

Buena parte de mi vida en el bachillerato y aun después de finalizarlo se movía en el deporte, sabía que tenía más posibilidades de trabajo, y eso significó tomar la oportunidad que me brindaron para estudiar. Estando en este medio como deportista también se abre la posibilidad de trabajar con los entes vinculados a ellos. Deporte y educación física van entrelazados. Me gustaba muchísimo el deporte, pero una cosa no tiene que ver con la otra, no es lo mismo el gusto por el deporte y el gusto por enseñar, para mí enseñar no era lo mío y lo decía porque no me sentía capaz de manejar un grupo, enseñar significaba tener dominio del grupo y frente a eso yo estaba mal. Pero ahora que tengo este dominio de grupo puedo hacer muchas cosas con los niños, puedo trabajar de una mejor forma.

Seis meses duré en esa lucha con mi hermana y aún después de iniciar mis estudios universitarios ella me decía; "oiga, retírese de entrenar y trabaje, usted puede pagar su estudio". Yo sabía que eso no era tan real, uno empieza a ganar plata y los estudios se abandonan, uno se queda con lo que tiene. ¡Entonces no! Yo tenía claro que no era amante a la educación física, pero tenía que terminar. Para aquel entonces vivíamos con mi mami, mi hermana y su hijo. Tiempo después mi hermana tuvo otro hijo y un año más tarde ella murió. Fue algo tenaz, ella murió cuando me faltaba un año para terminar mi carrera, dejó dos hijos, un niño y una niña. En ese entonces el niño tenía ocho años y la niña tenía uno. Yo continué entrenando, pero la ausencia de mi hermana me hizo renunciar. De inmediato me hice cargo de la niña y hoy tengo la custodia, es mi hija prácticamente. Me retiré porque yo trabajaba con el IDRD y en paralelo estaba estudiando, me quedaba muy difícil... ahh, debido a eso no puede clasificar a los juegos nacionales en el 2008. Yo estaba en preselección para los juegos nacionales, pero debido a todos esos problemas me fue muy mal, quedé cuarta y solo llevaban tres, tenía la marca pero no tenía la posición, y pues el IDRD y Bogotá siempre han apoyado a los deportistas que van a juegos nacionales, después de tener mi beca, mi alimentación, transporte y otras cosas más, lo perdí todo por no clasificar.

En octavo semestre ya no estaba becada, trabajaba con el IDRD y ganaba muy poco. Empecé a buscar otro trabajo obligada por la situación, además también estaban los gastos de la niña. El papá de la niña nunca respondió, nunca se ha interesado por ella; cosa muy diferente al papá del niño. Al principio me hice cargo de los dos, pero un año después y por circunstancias de la vida el niño se fue con el papá, yo me quedé con la niña, renuncié al atletismo, empecé a trabajar en un colegio y con el IDRD, tenía dos trabajos y para el entrenamiento ya no quedaba tiempo. Lo abandoné por todos esos problemas y también estaba cansada. En aquel entonces entrenaba por las mañanas, trabajaba en las tardes y en las noches estudiaba, llegaba muy cansada a la universidad y estaba adelantando la tesis. Eran muchas cosas y en el entrenamiento ya no estaba rindiendo, decidí abandonarlo. Finalizar mi carrera fue realmente significativo, con tantas cosas que hubo, uno dice ¡terminé! Nadie sabe de dónde viene y cómo se ha logrado. De mi familia soy la única profesional, de la cuadra pocos han llegado a serlo, creo que es una visión positiva, pero sobre todo, hecho con trabajo.

\section{Un espacio para los amigos...}

Por respeto, por valor y por afecto, déjeme y le cuento a manera de homenaje sobre aquellos que estuvieron apoyándome durante mi carrera. Ya lo sabe, Germán, Giovanny, mi hermana y mi madre ocupan un lugar aparte en este relato, pero mis amigos de universidad merecen una mención de honor aunque este solo sea un escrito que evoca 
la memoria. Ellos me miraban por encima de su hombro solo cuando me daban su mano para levantarme, me apoyaron económica y moralmente, hicieron eso que en Colombia llamamos "vaca" cuando estuve a punto de dejar mis estudios. De todas maneras ellos sabían que yo no contaba con recursos para estudiar. Una carrera universitaria no es solamente llegar allá y sentarse y escuchar las cátedras, ellos lo tenían muy claro y lo mostraron con su solidaridad. Hacer una carrera depende de muchas cosas, de mucho dinero, de mucha inversión y eso era algo con lo que yo no contaba. Solo tenía un trabajo con un sueldo injusto, y con la beca que al cabo del tiempo dejaría de serlo, y no contaba con eso que se requiere para estar en la universidad. Cuando me reunía con mis compañeros a hacer algún trabajo casi siempre me faltaba el dinero, ellos nunca lo pidieron de mí, lo daban sin asumir posturas de misericordia, me ayudaron con los transportes y con muchas cosas más. Todo con el propósito de ayudarme a continuar y no rendirme... me impulsaron a seguir. Pues así como dice el dicho: "mis amigos no son en cantidad sino en calidad". Desde los primeros semestres con ellos empecé y con ellos terminé. Me llena de orgullo recordarlos; Melisa, Pedro y Eduard. A pesar del apoyo que ellos me daban, ellos a veces notaban en mí la debilidad, a veces yo desfallecía y les decía que ya no podía más, que no quería seguir. Fueron muchas crisis durante la carrera, pero ahora que recuerdo y veo los logros me siento honrada de su presencia en mi vida y por supuesto siento un profundo orgullo al ser parte de las suyas.

Al igual que mis amigos, los profes siempre te dejan algo, así sean cosas para odiar como lo hizo Enrique, pero este no es el caso, tuve un gran profesor en la universidad con el que todavía hablo y a quien debo mucho. Wilmar Latorre fue un gran apoyo para mí, él me colaboró también emocional y económicamente, me ayudó bastante. Hace cinco años me gradué y todavía lo sigo, me sigue ayudando, me sigue apoyando. Él es un ser humano estupendo, como docente excelente, jexigente! Es muy dedicado, es juicioso, una gran persona que siempre estará cuando lo necesitas, Wilmar es de esas personas que creen en los otros. Le aprendí esa dedicación, ese coraje, el nunca desfallecer cuando estás haciendo las cosas, él empieza algo y ¡eso se tiene que terminar! Aprendí sencillez para ser profesor. Tuve la oportunidad de estar con él en las primeras prácticas, me enseñaba la forma de pararme ante los estudiantes, cómo hablarles a los niños, cómo dirigirme a las personas, cómo ser persona con las personas a las que enseñamos.

\section{Los matices de la profesión}

Cuando empecé a estudiar educación física me pareció chévere. Sin embargo, no estaba convencida del todo. Al empezar las prácticas en el colegio y al enfrentarme con los niños me pareció durísimo... Yo decía; ¡no! definitivamente me equivoqué de carrera. Estaba en séptimo semestre y aún creía que estaba equivocada, pero... primero, estaba estudiando gratis y segundo, ¡no...! Tenía que terminar, siempre terminó lo que empiezo.

Después de las experiencias en los colegios yo decía: ¡no! estoy equivocada, no quiero hacer esto, no tengo dominio del grupo. Ahora... creo que eso era normal. No cualquiera llega a pararse frente a un grupo de 40 niños que corren por todos lados. Realmente no sabía qué hacer, pero es la experiencia la que forma al docente. La universidad te enseña muchas cosas, pero es en el campo, en la cancha donde uno puede decir; jacá soy docente! Al graduarse le entregan un diploma, pero nadie le dice que los niños se manejan de un modo u otro, nadie dice usted tiene que hacer esto y esto no.

Desde el inicio de las prácticas con la universidad hasta poco antes de finalizar la carrera estuve dudando sobre mi vocación de maestra. Cuando más insegura me sentía ya estaba muy adelantada y no podía renunciar, además, me estaban pagando todo y no podía ser desagradecida. Llegar hasta octavo y negarme a continuar no era lo más sensato. Fue tenaz, dos años duré muy aburrida dictando clases, pero "la práctica hace al maestro" dice el dicho. Todo esto me sirvió para recoger experiencia y ahora me encanta trabajar con niños, ya es fácil, ya sé manejar el grupo y sé cómo tratarlos. Ahora es fácil y muy chévere. De verdad que es muy chévere trabajar, y lo mejor de todo es que te pagan por algo que te gusta. Me siento muy gratificada por eso, siento que es una labor muy bonita. Uno juega un papel muy importante en la vida de los niños. Si los tratas bien ellos se van a enamorar de ti, serás uno de sus amigos, un compinche, y así tiene que ser, a veces debemos comportarnos como un niño, ser un niño, no dejar de serlo.

Me gusta muchísimo mi trabajo porque estoy en lo que a mí me gusta, entrenar niños. Me gusta porque ellos van por gusto, por amor a la clase y sin presiones. Eso es lo que no me ha gustado de la educación física... la clase. Hay niños que no les gusta el cuento, van a educación física con pereza, sin querer hacerlo, mejor dicho, toca esforzarse más, y no es que me guste la cosa fácil, pero se pierde interés. En el deporte entrenas al niño y rápidamente empiezas a ver los resultados, es una satisfacción. En cambio en educación física tú los 
ves una vez por semana, siempre está el desorden, uno no ve el proceso, no ve los avances.

Cuando uno trabaja en un oficio como este, debe tratar [de] que los niños se enamoren de lo que haces; de por sí, a los niños les gusta mucho la clase de educación física. Es necesario asumir compromiso. Si tratamos un juego, entonces, este debe ser dirigido. Muchas veces el maestro de educación física toma una pelota y se la pasa a los niños para que jueguen sin hacerse responsable de lo que pasa allí. Enseñar en educación física no puede volverse un hacer por hacer. Lo importante es la vocación docente, percibir ese amor que los niños te toman, ese respeto es importante porque tú sabes que lo hacen por la clase, y esta es la oportunidad para ayudar a todos los que estamos ahí. ¿Sabes? Las primeras clases que di me sentía perdida, pero gracias a los apoyos de los docentes que tuve pude hacerme una mejor docente. Para mí, un buen docente es el que se mete a la cancha con los niños, vive y aprende junto a ellos, no ese docente que siempre está renegando. La educación física debe contar con buenos docentes que hagan notar su importancia para una mejor calidad de vida. Enseñar me inquieta cada día. Me gusta brindarle conocimiento a los niños, cosas que muchas veces las obtengo en mi diario vivir en el deporte. Mi experiencia como deportista me da la oportunidad de enseñar entereza y fortaleza, me gusta que conozcan un buen camino y la satisfacción del deporte. Me gustaría ser entrenadora de rendimiento y representar al país junto con esos niños, es un reto. En cinco años me gustaría hacer una especialización en entrenamiento deportivo y estar ejerciendo como una entrenadora reconocida.

Debo confesar que la mayoría de mi trabajo ha sido con escuelas deportivas aunque en otras ocasiones lo hice en colegios. Hoy trabajo en un colegio como instructora de atletismo y patinaje, y también lo hago en un municipio cercano. Sin embargo, trabajar el colegio es muy difícil, ya sabe por qué, son muchos niños corriendo por todos lados, incontrolables, indescifrables. Hace un año tuve la oportunidad de trabajar en un colegio en educación física y hace dos años también lo hice en otro pero debo confesarle que no me sentí tan enamorada como me siento con la formación deportiva; como entrenadora me siento más cómoda. Parte de todo esto se debe a que en la clase de educación física, como en todos lados, están los que les gusta y los que no. Rico trabajar con lo que sí, pero es molesto presionar a esos que no les gustaba, por eso me gustó más el ámbito deportivo, allí llegan los niños que quieren, los que están dispuestos a trabajar en ese deporte, no hay que pelear con nadie para hacer las cosas. Pero déjeme y le cuento como fue mi paso por estos colegios; en el primero duré relativamente poco, hicieron recorte de personal y como había muchos profesores de educación física, esos fueron los primeros en salir junto con aquellos que llevaban poco tiempo, entre esos yo. Me gustaba mucho porque era un colegio de monjas, sólo niñas y muy decentes, muy bien llevadas. Lo que no me gustaba era el relleno del colegio, era un colegio privado y nos ordenaban dictar clases de todas la áreas; de sociales, matemáticas, religión, de todo. Era algo para lo que no estábamos capacitados. Si te tocaba con primaria podías defenderte, y aun así, ya se me habían olvidado muchas cosas. El otro colegio fue tenaz, pertenecía a un municipio y había niños muy groseros, muy desordenados. El coordinador no tenía orden ni control con los niños, todos les pegaban a todos, incluso conmigo lo hicieron; dos niños me agredieron, no respetaban a nadie, ni a la mamá, a nadie; ¡una gaminada! no me gustó estar allá. Si el coordinador, el rector, o la persona a cargo tiene claro lo que quiere no se presentarían cosas como esas, los alumnos respetan, pero sin orden... entonces grave. También depende de los papás, al ver más allá de esos niños, estos ni siquiera tenían la culpa, eran niños sin papás, sin mamás, vivían con el abuelo, con la tía; detrás de ellos se notaba un conflicto social tenaz. Salí del colegio por terminación de contrato, igual me llamaron al año siguiente para continuar, pero es un municipio muy lejano, tenía vivienda, y gracias a Dios me salió trabajo acá en Bogotá, prácticamente rechacé el ofrecimiento.

Durante mi periodo de formación universitaria tuve la oportunidad de empezar a trabajar con el IDRD. Yo estuve becada ocho semestres, cuando perdí la beca fue mi trabajo y mis vínculos con el deporte [sic] los que me permitieron finalizar, el IDRD me había vinculado en uno de sus programas. Poco tiempo pasó y me di cuenta [de] que me llamaba la atención el entrenamiento deportivo. Antes había hecho prácticas en un colegio y eso me pareció bastante duro. Cuando empecé a trabajar en el IDRD en un deporte específico, ahí fue cuando me empezó a gustar mucho más la educación física, me di cuenta [de lo] que era tomar al niño y llevarlo a otro punto. Llevar a ese niño que no sabe correr y que lo hace todo desbaratado a un punto donde empieza a correr bien, donde hace sus movimientos adecuados. Saber que uno fue quien influyó en eso es muy gratificante, ¿sabes? creo que la sociedad no ve la educación física como algo importante, ellos toman la educación física como juego, como ¡ah! ¡Tome este balón y vaya patéelo! para la sociedad hay otras cosas más importantes como la tecnología, como los centros comerciales, como la vitrina. Algo muy similar ocurre con las opiniones de otros profesionales, en especial nuestros colegas de otras áreas; 
dicen que los edufísicos somos unos vagos, unos echados, unos irresponsables que nunca cumplimos, que hacemos la tarea más fácil, ellos lo ven así, creen que es sacar los niños y ponerlos al jugar con una pelota, pero así como hay profesores buenos, también están los malos, y nada de eso significa que la educación física sea solamente coger una pelota para patearla. No es solamente patear, es desarrollar en los niños que tenemos a cargo, ciertas habilidades y destrezas para la vida.

Mi mayor placer en este oficio ocurre cuando ves triunfar eso niños que has entrenado, es maravilloso hacer parte de esa satisfacción que ellos expresan al saber que son buenos, que tienen talento. Es muy emotivo compartir esa felicidad cuando toman su medalla y te agradecen por eso, por el apoyo y por estar ahí. En muchos eventos los niños se acercan a mí antes que a sus padres. “iMire profe, sí pude!”. Ellos comparten sus logros conmigo, son los mejores maestros de todos, te dan la mejor de las experiencias, te reconocen como la fuerza que alienta el proceso. Es satisfactorio cuando se logran los encuentros con otras escuelas o con otros centros deportivos. Ver a tus niños, reconocer sus mejoras y triunfos muchas veces me recuerda esos momentos que me llenaron de felicidad y valor. ¡Se revuelven tantos sentimientos! Volver a tu infancia y notar que esas alegrías marcaron tu camino. Las generaciones han venido cambiando pero no dejamos de ser niños. Me gustaría seguir con este proceso, continuar con estos niños y sacarlos como campeones, quiero que estos niños me recuerden, así como yo recuerdo lo que hizo Germán Olaya por mí, quiero que esos niños también me recuerden así, que tiempo después puedan decir; "tuve una profesora que gracias a ella soy importante para la sociedad".

Ahora que soy profesional y trabajo en un colegio, la educación física la enfoco sobre las habilidades motrices y por supuesto sigo con mi pasión "el atletismo", entreno fuerte para mantener un alto nivel, lo hago en diferentes lados, donde esté a la mano, si voy para el trabajo me voy corriendo, si no tengo que trabajar entreno en el Tunal, si no, en el Salitre... donde se pueda. A mi hija trato de inculcarle el gusto por el deporte, con ella salimos a montar patines al Tunal o a Villa Mayor. En ocasiones también vamos con mis sobrinos a quienes también les gusta mucho el deporte, a mi mamá le encanta que siga entrenando, le encanta lo que hago.

\section{CONSIDERACIONES FINALES}

Desde el punto de vista de la investigación histórica en el campo de la educación física, este relato ha aportado un nuevo paisaje de observación complejo y fértil que articula las experiencias del sujeto con los elementos sociales y humanos de la formación en la profesión- En este sentido, se muestra ante los investigadores y formadores de y en la educación física los nudos que van tejiendo las realidades en las cuales se insertan como profesionales, como personas, y como actores y protagonistas de la historia. "[L]os hombres se parecen más a su tiempo que a sus padres" recuerda el historiador Marc Bloch (1996, p. 64), citando un viejo proverbio árabe; así las cosas, este ejercicio investigativo se plantea como el inicio de nuevas investigaciones que permitan reconocer en cada sujeto su margen de acción, sus determinaciones y sus puntos de quiebre dentro de las estructuras sociales.

Frente a lo anterior, este ejercicio presenta un significativo avance de cara a reflexionar las formas de construir y de determinar los conocimientos que circulan en la educación física. Sin embargo, es necesario intensificar este tipo de esfuerzos, pues la historia de la educación física se encuentra enmarcada dentro de los cánones de la historiografía, de los cambios y ajustes a las normativas, a las decisiones estatales y de Gobierno, todas ellas dentro de la lógica macroestructural, estatal e institucional. Estas relaciones han dejado de lado los procesos y sucesos de una historicidad que se vive en las aulas, en los patios, en los caminos y en muchos otros espacios y relaciones que la dinamizan y le dan cuerpo. Según Chinchilla (1998a), la negativa al pasado por parte de la educación física ha generado poca atención en nuestra propia historia como disciplina. Esto ha desembocado en la pérdida de información valiosa que justifica el trasegar de sus actores y las decisiones que frente a ella toman sus miembros e instituciones.

La educación física está obligada a comprender con mayor profundidad su propia cotidianidad; el reconocimiento de su propia imagen, de su propio cuerpo y de sus transformaciones ha de pasar por la identificación de sus actores y sus procedencias; es necesario conocer esos mundos que quedan por fueran de los contenidos, de la evaluación y de su didáctica tecnificada. La educación física forma, y la forma no es otra cosa que las contingencias del tiempo. Hablar de tiempo en educación física obliga a considerar los cambios y las prevalencias. En consecuencia, las miradas que recaen sobre los sucesos y las personas implican observar el contexto temporal, sin olvidar que las circunstancias son dinámicas y cambiantes, pero a la vez prevalecientes; 
por tanto, su influencia sobre la vida del sujeto es consecuente con su lógica de transformación. Esto significa que las relativas afectaciones que la educación física ejerce sobre las personas contribuyen a su estructuración como campo de saber; en este sentido, la cronología experiencial del sujeto, vinculada a un marco de referencias colectivas, denota un importante e interesante escenario epistemológico.

Finalmente, problematizar la educación física y su devenir en el tiempo a partir de las voces, relatos y narrativas de quienes la viven cotidianamente permite explicar hasta cierto punto el conjunto de sentidos y significados que subyacen en la relación que cada individuo entabla con el modelo preponderante de la disciplina. En buena medida sus acciones y reacciones están determinadas por lo vivido, en consecuencia la historicidad de la educación física debe constituirse en un acto consciente. Entre sus actores debe formarse para la acción, no solo desde las posibilidades motoras, sino en virtud del sentido humano, pues mediante este se invita a conocer el pasado de la disciplina y se plantean estrategias que permitan dinamizarla en su cotidianidad.

\section{REFERENCIAS}

Arcila, P., Mendoza, Y., Jaramillo, J. y Cañón, O. (2010). Comprensión del significado desde Vygotsky, Bruner y Gergen. Diversitas, 6(1), 37-49.

Atkinson, R. (1998). The life story interview (Qualitative Research Methods Series, vol. 44). Thousand Oaks, CA: Sage.
Carvajal, A. (2005). Planeación participativa: diagnóstico, plan de desarrollo y avaluación de proyectos. Santiago de Cali-Colombia: Universidad del Valle.

Chinchilla, V. (1998a). Historiografía de la educación física en Colombia. Revista Colombiana de Educación, 38(39), 101-116.

Chinchilla, V. (1998b). La educación física en el proceso de la modernización. En Memorias Encuentro de Investigadores. Universidad de Campinas, São Paulo.

Contecha, L. (2000). La educación física y el deporte en Colombia. Una historia. En Lecturas, educación física y deportes (pp. 1-4).

Ferrarotti, F. (2000) Las historias de vida como método. Convergencia. Revista de Ciencias Sociales, 14(44), 15-40.

Gómez, A. y Parra, L. (1986). La educación física como profesión 1936-1986. Bogotá: Universidad Central.

Manayay, E. (2010). Lectura analítica del texto escrito: bases didácticas y actos didácticos. Revista de Educación, Cultura y Sociedad, 9(19), 41-49.

Ministerio de Educación Nacional. (2010). Documento numero 15; orientaciones pedagógicas para la Educación Física, Recreación y Deporte. Recuperado de http:// www.mineducacion.gov.co/1759/articles-340033_ archivo_pdf_Orientaciones_EduFisica_Rec_Deporte.pdf

Vaca, A. (1987). Historia de la educación física colombiana a través de sus normas. Bogotá: Universidad Central.

Vaca, A. (1993). Historia del alma mater de la educación física colombiana. Bogotá: Universidad Pedagógica Nacional. 